\title{
The Two Faces of Janus: Delay in Metropolitan Trial Courts
}

\author{
By Maxine Boord Virtue
}

\begin{abstract}
Recent studies show that metropolitan trial courts have far larger case-loads than other courts. These loads differ in substance from those of nonmetropolitan courts, being disproportionately weighted with special types of cases, such as criminal, mental, alcoholic, traffic, domestic relations cases, and litigation otherwise related to the special behavior of metropolitan populations. Metropolitan court systems usually are complex, overlapping, and not adjusted to the geographic area to be served. Because of the special structural patterns of metropolitan courts, and the special conditions under which they operate, delay in disposing of cases is especially and predominantly a metropolitan court problem. In these courts, ever increasing pressure to speed up the tempo of justice is balanced by the need to avoid perfunctory routine disposition, so as to defeat the very purpose of seeking justice. To overcome both aspects of this leering monster--delay and perfunctory routine-is the special problem of metropolitan courts.
\end{abstract}

Maxine Boord Virtue, LL.B., Ypsilanti, Michigan, is an Assistant Attorney-General of Michigan, currently engaged in preparing for the University of Michigan Law School and the Section of Judicial Administration, American Bar Association, a final monograph* to conclude the inquiry launched by the Section in 1947 into the problems of metropolitan trial courts. Mrs. Virtue is a graduate of the School of Law, Yale University. In addition to the original Detroit study cited herein, other books by the author include: Basic Structure of Children's Services in Michigan (1952); Judge Medina Speaks (Editor, 1954); Family Cases in Court (1956).

* The material in this article is taken from the monograph now nearing completion. 
$\mathbf{F}$ OR the last decade the staff and membership of the Section of Judicial Administration of the American Bar Association have been working with local leaders of bench and bar, and with scholars in various fields, to isolate and analyze the special problems of metropolitan trial courts. Conclusions from this series of inquiries are now being placed in final form. Special metropolitan court problems are thought to occur both in the structure and in the operation of metropolitan courts. As a consequence of these special problems, delay is likely to result both from the structural patterns characteristic of the metropolitan court system, and from the special conditions under which metropolitan courts must operate.

Therefore, delay is especially and predominantly a metropolitan court problem. Although not confined exclusively to metropolitan courts, delay is virtually always found there. It is more difficult to deal with there than elsewhere, because of the complicated nature of the metropolitan court system, the complex mechanisms necessary to move cases through the system, and because of the great numbers of cases handled in metropolitan areas. In such an environment the causes of delay are harder to find and eradicate than in a simple one-judge court with a small case-load, such as may serve smaller communities.

Then, too, in a metropolitan court system the problem of achieving prompt disposition of cases is further complicated by the other face of Janus: in the densely populated case-load of the metropolitan court, there is a special danger that some of the cases will be completed too fast, so that perfunctory, routine disposition will be made of some problems that should receive more prolonged or more specialized attention in order to achieve a just disposition. This danger is most feared in the personal problem cases, where too-prompt disposition of a criminal sexual psychopath, a divorce, an adoption, a juvenile case may sow the wind that will later reap a whirlwind of community depredation and personal tragedy. It is true that the metropolis is likely to have more specialized facilities for assisting the court to arrive at a proper evaluation of such personal problem cases. On the other hand, the much larger case-load of the metropolitan court and the bewildering complexity of its departments as related to complex noncourt agencies, also concerned with such cases, combine to make it harder for the metropolitan judge to be sure of quickly assembling and consulting the sources from which that solution can be reached which will best protect the community and dispose of the litigation.

Thus, delay is a two-faced specter which confronts the judge of the metropolitan trial court whichever way he turns: from one side leers the danger of delaying disposition until the problem is insoluble; from the other, the danger of hurrying too quickly to a disposition which will result in further conflict and litigation.

\section{Metropolitan Communities}

As Hawley and others have pointed out, the metropolitan community, embracing cities, villages, and other local governmental units within a radius of thirty-five or more miles from the mother city, has assumed a dominant position in the settlement pattern of the United States. In 1950, the 168 metropolitan areas contained 56 per cent of the nation's population. By 1956, the total population had increased 9.8 per cent; within the metropolitan areas the growth rate was 14.8 per cent, while outside, it was only 3.4 per cent. ${ }^{1}$

${ }^{1}$ Amos Hawley, The Changing Shape of Metropolitan America: Deconcentration since 1920 (Glencoe, Hlinois: The Free Press, 1955). 1 et seq. Department of Commerce, Bureau 
More than half our population is living in metropolitan areas, and the trend appears to be continuing strongly.

Moreover, the metropolitan area acts as a magnet for industrial, social, and other activities of people in the surrounding territory. Therefore, we expect to find, and we do find, that metropolitan courts have to deal not only with the litigation of the inhabitants of the metropolitan area, but also with the many cases caused by some aspect of the movement in and out of the central city, or some conflict in the complex of relationships between in-dwellers and out-dwellers. Where a choice of tribunals is possible, litigants appear to prefer the metropolitan court, since as a function of the metropolitan community it shares the magnetizing power and prestige of the metropolis.

\section{Governmental Complications}

Exaggerated proliferation of overlapping governmental units is a concomitant of virtually all metropolitan areas. Congestion and mobility of population, two characterizing factors of metropolitan communities, combine with other forces to push the real community beyond the original legal boundaries of the mother city and thus create pressures which result in the improvised and haphazard creation of special governmental units to meet the needs as they occur. $^{2}$

This haphazard complexity of governmental units is in and of itself a breeder of litigation in metropolitan courts, adding to its already huge case-load. For example, the struggles of cities to annex

of the Census, Current Population Reports, Series P-20, No. 71, "Civilian Population, by Metropolitan and Urban-Rural Residence: 1950 and 1956."

2 See, generally, Council of State Governments, States and Metropolitan Problems. (Chicago, 1956), p. 15. The Annals, Vol. 314 (Nov. 1957), especially "Metropolitan Organization," by Luther Gulick, 53 et seq. suburban territory and the resistance of such territory to inclusion in the city are currently a major source of litigation in all metropolitan areas-a function of their growth and change. Many metropolitan areas, indeed, now involve several states, and a few involve two countries.

The way in which this governmental complexity is reflected in the condition of the courts' load of litigation may be suggested by current efforts, as reported in the New York press, to develop a tristate legal tribunal capable of dealing with litigation arising out of waterfront labor problems.

Many of these overlapping governmental units, which occur in metropoli$\tan$ areas, have the power to develop independent judicial tribunals, with competing or conflicting jurisdiction; moreover, they are not integrated to the needs of the metropolitan area. Thus, in 1932, Lepawsky found 556 autonomous courts in the Chicago metropolitan region, and 205 in Cook County alone. This writer found 145 judicial tribunals in the Detroit Metropolitan District in a study conducted in 1948-1950. And even in California, which has unified its court system, a recent study in Los Angeles has brought out the fact that unification of the major trial court, the Superior Court, is hampered administratively by rapid proliferation of separate branch courts, and that the multiplication of separate municipal courts in Los Angeles County is creating a problem. ${ }^{3}$

\section{Distributron of Population}

Presently, the impact of governmental multiplicity upon delay in metropolitan courts is further compounded by the dis-

3 James G. Holbrook, Survey of the Metropolitan Trial Courts: Los Angeles Area (Los Angeles, California: University of Southern California Press, 1956), pp. 36-37. This study is one of the series conducted for the Section of Judicial Administration. 
tribution of the population within the metropolitan area: typically, the shift is towards the suburbs: "centrifugal drift," as population students call it. This tendency has accelerated in the decade since the Detroit study, which shows high growth rates shifting from the centers towards the outlying parts of metropolitan areas, and the population of satellite portions of such areas rapidly increasing.

Thus, to the problem of a multiplicity of overlying and overlapping governmental units within a given metropolitan area is now added the problem of scatter -a vast deconcentration towards the periphery into satellite settlements, occurring along with and as a major thrust of a continued vigorous over-all rate of growth of metropolitan areas as a whole.

Another characteristic of metropolitan population is density-in Detroit, for example, the population per square mile in 1950 was 13,249; in Boston, 16,767; in New York, 25,046; in Chicago, $17,450 .{ }^{4}$ Hawley reports that in some sectors of our largest cities, the density factor surpasses $100,000 .{ }^{5}$

As Professor Holbrook points out in commenting on the density of Los Angeles, "multi-million dollar lawsuits are commonplace and murder trials are daily occurrences which attract no attention unless a green orchid was found on the corpse." $\mathrm{B}$

\section{MOBILITY}

The great mobility of metropolitan populations merits closer examination in terms of its bearing upon delay-producing conditions in metropolitan courts. Numerous kinds and levels of migration occur continually to and from the core

${ }^{4}$ United States Bureau of the Census, County and City Data Book, (1956), "A Statistical Abstract Supplement," (1957), Tables 3 and 4, pp. 346 et seq.; 365 et seq.

${ }^{5}$ Amos Hawley, Human Ecology. (New York, N. Y.: Ronald Press, 1950), 102.

${ }^{6}$ Holbrook, op. cit., note 3 supra, p. 11. of the metropolitan area. These tidal waves of human movement are basic to the existence of the metropolis and set the unique tone and tempo of its life. "Each great capital sits like a spider in the midst of its transportation web." 7

More than elsewhere, the residents of metropolitan communities are made up of recent migrants, many from outside the state, many from outside the country. The attraction of the large metropolitan area upon long-range migrants is one of its strongest characterizing attributes. This means that in the corecity, there will be more foreign born and negro population, less native-born white population. And, in turn, this comparative ethnic heterogeneity expresses itself, in terms of court problems, in class and race tension, in increased criminality, and in all sorts of personal problem litigation arising out of failure of migrants from different ethnic and culture groups to adjust to the demands of the new community. For example, the 1944 race riots on Belle Isle, in Detroit, are said by local court and police personnel to have been the result of a clash between native-born Detroit negroes, moving about the city with considerable self-confidence, and recent migrants brought in to work in the automobile plants from rural white settlements in southern and border-southern states. Similar incidents could be adduced concerning Mexicans in the Texas and California metropolitan cities, concerning Puerto Rican migrants in New York, and so on. The point here is that the ever present, large-scale mobility and congestion in any metropolitan city make such clashes an integral part of the city's life, and thus are

${ }^{7}$ Wilfred Owen, The Metropolitan Transportation Problem (Washington, D. C.: Brookings Institute, 1956), citing Holden, City of London, a Record of Destruction and Survival. 
present as permanent elements of its law enforcement and court administration problem.

\section{The daily commuter}

Another aspect of the mobility factor, as it clogs the dockets of the metropolitan trial courts, is the daily commuter traffic. The large central cities continue to grow, and with them, their transportation problems. Improved transportation has also rendered these central cities accessible in a day to an ever widening circle of satellite city-dwellers. Thus, the problem now is not only how to move, but how to find room to move, and how to find a place to stop. ${ }^{8}$ Half of all motor travel in concentrated in the United States in central cities of metropolitan areas, and more than half of all persons entering and leaving metropolitan areas with populations of over 250,000 are moving by automobile, Owen reports. ${ }^{\circ}$

Consider, then, the commuter: the New Yorker in the five o'clock subway rush, the Angeleno caught in a vast rush-hour traffic jam on the Freeway. These are not occasional traumatic experiences, they are part of the daily rhythm of life of a substantial majority of our population. As Hawley points out, the entire tempo of life is quicker in the metropolitan city, relationships more transitory and enervating. It represents the extreme in modern life. Its nerve centers are the points of most feverish activity.

By bringing into instantaneous focus the opportunities, the risks, and the tragedies of life, man's behavior is made to resemble that of an animal treated to a rapid succession of electric shocks. It is not surprising that the incidence of mental disorder is highest in metropolitan centers. ${ }^{10}$

\footnotetext{
${ }^{8}$ Ibid., pp. $2,3$.

${ }^{9}$ Ibid., p. 33.

${ }^{10}$ Amos Hawley, Human Ecology, note 5 supra, pp. 306-7.
}

We find "mobility," then, which is a metropolitan characteristic, expressing itself in the metropolitan court's caseload in several ways: not only in a tremendous load of traffic, property damage, and personal injury cases, but also in a wide variety of cases, such as mental cases, arising out of human reaction to the repeated shocks of the metropoli$\tan$ environment. It is important to note that many such cases cannot be adequately dealt with by the metropoli$\tan$ court by application of the adversary process for a single day. Rather, many such require expert diagnosis, and some knowledgeable supervision over a period of months or years in order to rehabilitate or readjust the human being who has come into the case-load of the metropolitan court as a result of "battle fatigue" suffered in the daily routine of metropolitan life.

\section{Litigation-PRone PopUlation}

The ingredients of the total human aggregate in the core-city of a metropolitan area differ, and differ in certain specific ways, from those of the aggregate of a nonmetropolitan area. As has been mentioned, there are more foreign born and nonwhite in the metropolitan area. It is also known that the percentages of single, widowed, and divorced persons are directly related to the size of the place. ${ }^{11}$ Further, the phenomenon of "centifugal drift" marks the consistent strong movement of stable family groups to withdraw from the central core of the metropolis, seeking the greenbelts of suburbia to bring up their children.

This means progressive deterioration of neighborhoods near the heart of the central city, the progression of which from single-family dwellings to boarding houses to blighted area to slum has been traced and diagrammed in a number

\footnotetext{
${ }^{11}$ Otis Dudley Duncan, Social Characteristics of Urban and Rural Communities (New York, N. Y.: Wiley, 1956), p. 33.
} 
of studies. This progress is typically marked by the influx of various ethnic and cultural groups, each in its turn crowded out by a successor group less assimilated culturally with the original native population of the mother city and less able socially and economically to sustain itself while undergoing assimilation.

The gang delinquencies in New York, for example, are typical of the conflicts generated by lacings of different ethnic social groups moving about in the congestion and squalor of a neighborhood populated by trouble-prone groups. Dependency is another population characteristic known to be greatest at the heart of the central city. The incidence of receivers of relief and various kinds of public assistance is highest in the congested areas near the core of the metropolis. Illegitimate births are comparatively much higher there. Destitution is also reported to be directly related, in incidence, to vice, crime, and mobility. It has even been suggested, recently, that some of the new public housing projects actually build into their population such disruptive factors as dependency, destitution, and maladjustment, by the way their policy for screening applicants is developed and admin-

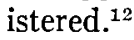

Another aspect of the concentration of dependency and destitution at the city's heart as related to the court's delay problem is the so-called "multiproblem family." It is said that in New York there are approximately 20,000 such families, representing less than 1 per cent of the population, but constituting the source of 75 per cent of all delinquency. A recent study in St. Paul by Bradley Buell Associates has established the accuracy of the "multi-problem family" concept. There it was found

\footnotetext{
12 See, for example, Harrison E. Salisbury, "The Shook-up Generation." New York Times, March 20-30, 1958.
}

that of 41,000 families receiving help from 109 tax-supported and voluntary health and welfare agencies in the area, a "small, hard knot" of 6,500 , about six per cent of the families, accounted for more than half of the total case-load served by these agencies. It is these same families that wind endlessly in and out of the metropolitan courts, often in contact with four or five courts at once. ${ }^{13}$ Their presence, in the metropolitan case-load, tends to slow the already clogged dockets to an even slower pace.

Here we should insert a "caveat" against the other face of Janus. Persons coming from areas known to contribute more than their share of certain kinds of litigation-such as, juvenile delinquency-are subject to what sociologists describe as "categorical risk." That is, a boy coming before a juvenile court, if a member of a certain minority group living in a certain area, has-to be blunt about it-two strikes on him.

This means that the court, under tremendous pressure to move the heavy case-load faster, also encounters here the vital problem of assuring a fair hearing and an appropriate disposition to each individual defendant. To do this and do it properly takes time-the more categorical risk, the more time.

\section{Metropolitan Conditions Reflected in Court Problems}

When we talk about a "metropolitan community," as referring to the behavior of all persons found within a geographic area, we are of course talking about not just one community but an infinity of communities. Thus, within any metropolitan area there are many people whose lives and movements are guided from a metropolitan center other than

${ }^{13}$ Maxine Boord Virtue, Survey of Metropolitan Courts: Detroit Area (Ann Arbor, Michigan: University of Michigan Press, 1950), p. 233 et seq. 
the one in which these people happen to have legal residence. For example, air line personnel literally commute to international capitals; those in communications, entertainment, and the top echelons of the industrial, academic, and governmental worlds commute to Washington, New York, and abroad.

Likewise, within the territorial limits of one metropolitan area, there are an infinite number of lesser communities marked out by business, educational, aesthetic, and cultural categories: the Polish community, the neighborhood community in the dormitory suburb, the beatnik crowd, the union brotherhood, the faculty community of the local university, the dwellers in the world of music, and so on. Each of these has its regular orbit, which governs the movement of those tuned to it, within and as a part of the vast series of movements which make up the rhythms of the metropolitan community as such.

Clearly, we can't have a court for each of these "real," or cultural, communities, nor can we have a single gigantic metropolitan court for each metropolitan area as a whole. The physical distances alone would prohibit such a "supercourt" as the latter, and even if distance is left out of account, such a tribunal would be too unwieldy to cope with case-loads which move and change in many unpredictable ways. Two factors only are fully predictable: growth, and continuous change.

\section{Stze and Delay}

A correlation between size of population and extent of court calendar delay has been shown to exist. See, for example, the current (1958) report of the Institute of Judicial Administration on The State of the Calendars of State Trial Courts, at page ii, with respect to personal injury jury cases. At page iii: "Only six courts appear on this year's list of jurisdictions having delay of over twenty-five months, and all 11 are situated in counties with populations of over $500,000: \ldots$.

\section{Multiplicity of Courts}

Multiplicity of governmental units, as has been pointed out above, is found in courts as in other metropolitan units of government. Confusion, overlap, and conflict of jurisdiction among these courts is the inevitable accompaniment. As one of the Detroit reporters once expressed it, there is "one court for the corned beef, one for the cabbage": one court for the divorcing parents, another for the child suffering from the effects of that divorce; one court for the rapist, another for the victim, and so on.

The disadvantages of court multiplicity, then, are first and most obvious, jurisdictional conflict and confusion. This is aggravated by the great size of the case-load, by the large numbers of persons attempting to deal at any time with any given unit in the case-load, and, in personal problem cases, by the presence of a multiplicity of social agencies also concerned with the problems which have resulted in litigation, and by each agency's determination to solve the problem independently.

Administratively, then, we expect to find, and we do find, that delay and confusion result from the coexistence of many courts with wholly or partly duplicating jurisdiction. See, for example, the docket check of the Circuit and Superior courts of Cook County conducted by this writer for the metropolitan court studies of the Section of Judicial Administration. ${ }^{14}$

14 Committee on Metropolitan trial Courts, Progress Rep., p. 26 et seq. (June 1953). In February 1953, a check of the printed calendar of the Superior Court showed 350 cases filed in 1945, and 342 cases filed in 1946, still undisposed of. The average docket life of a group of cases checked in this court was 32.6 months, the median case had a docket life of 36 months. In the Circuit 
Multiplicity of courts has been regarded since $1913,{ }^{15}$ and earlier, by students of judicial administration as one of the signal causes of delay, and as a shocking waste of judicial power in large cities. The delay, and the waste, is increasing rapidly with the surge of population into metropolitan areas.

A recent study has described the process of growth of competing and duplicating courts which has accompanied the urbanization of our people. The authors list relief from congested calendars, need for better disposition of special types of cases, and far-reaching social change, as causes contributing to still further development of multiple courts within metropolitan areas. ${ }^{16}$

\section{Stze of Case-Load}

The most direct reflection of the population grouping known as "metropolitanization," as it affects the delay problem in metropolitan courts, is, of course, the sheer, overwhelming size of the case-loads in metropolitan courts. To convey some idea of the awesome size of this load, the writer's worknotes, taken in 1947 for the original Detroit study, contain the record of an attempt made to estimate the full work-load for the entire system of courts in the Detroit metropolitan area. A difficult task, for almost nowhere can be found proper statistical reports of the work of all trial courts in a metropolitan area, so integrated as to provide this simple information.

Court, a check of a small group of cases showed over-all average docket life of 24 months; the median case had a docket life of 26 months.

15 Roscoe Pound, Administration of Justice in the Modern City, 26 HaRV. L. REv. 302, 313 (Feb. 1913).

16 Council of State Governments, Trial Courts of General Jurisdiction in the 48 States, (Chicago, Illinois: William L. Frederick and Sidney Spector, 1951), p. 2 et seq.
The total case-load disposed of in 1947 by trial courts convening in Detroit was 677,879 cases. This figure we know to be low, since it omits from the case-load of the juvenile division of the Probate Court several hundred adoption cases referred to that division for investigation. Also omitted are Recorder's Court condemnation cases and ordinance cases disposed of by that court's Traffic and Ordinance Division, since no figures were available. These figures include only cases disposed of in the immediate Detroit area, excluding the other two counties which are included in the Census Bureau's definition of the Detroit metropolitan area as it was defined for 1950.

According to the figures of the Michigan State Court Administrator for 1956, the Detroit area has a total case-load almost four times as large as that of any circuit outside the metropolitan area. Total cases commenced in all circuit courts in Michigan, as reported by the State Court Administrator for 1956, were 59,341. Of these 19,979 were filed in the Circuit Court of Wayne County; 6,311 in the felony division of Detroit Recorder's Court-city cases at circuit court level; 2,878 in Macomb County; 5,779 in Oakland County - a total of 34,947 for the entire Detroit metropoli$\tan$ area, or far more than half the total for the entire state.

Professor Holbrook reports ${ }^{17}$ that in the fiscal year 1953-1954, more than 100,000 cases were filed in the Los Angeles Superior Court (general trial jurisdiction), and 1,154,401 in the Los Angeles Municipal Court that same year. In 1954, a total of 221,398 cases were filed in all the California superior courts; the total filings in that year in Los Angeles alone were 108,968-almost half the total for the entire state. This relationship is more impressive when one

\footnotetext{
17 Holbrook, op. cit., note 3 supra, p. 12, and Table 2, p. 14.
} 
recalls that there are several major metropolitan areas in California, the San Francisco area, in addition to Los Angeles.

Further multiplication of statistics would not further advance the point: the case-loads of courts in the large central cities of metropolitan areas are of such tremendous size as to confront courts convening in those areas with conditions quite unlike those anywhere outside such areas. This characteristic condition-gigantic case-loads-makes itself felt in the form of delay, and also in the form of many complex structural, administrative, quantitative, and qualitative problems-all of which also bear upon the problem of delay.

\section{Special Types of Cases}

Is the metropolitan case-load not only bigger, but also different? Some difference in substance, in social texture, can be seen if only by reason of the fact that the bigger the case-load, necessarily the smaller each unit in it must be in relation to the whole. This fact alone indicates the importance, in considering delay, of looking hard at the special difficulties experienced by the metropolitan court in performing its judicial function adequately under conditions in which the aggregate case-load is so large as to render the individual case all but invisibly small.

This point aside, however, there is another way of looking at the difference in substance of the metropolitan caseload. Numerous studies have established the tendency of certain types of cases to predominate in metropolitan areas, and particularly in the central cities. Among these are criminal, domestic relations, traffic, mental, and certain other cases coming into court by reason of the special conditions governing behavior of persons in metropolitan areas.

In the attempt to provide special facilities for dealing with the social problems in these special types of cases, the metropolitan court finds itself confronted with the danger of transformation into a general rehabilitative clinic for personal problems, on the one hand, and, on the other, with the danger of sacrificing the rights of litigants to the increasing pressure to speed up.

To go too far in either direction is to sacrifice the vital force of the judicial function as such. Our studies indicate that judges in metropolitan trial courts are well aware of the danger leering from either side and are confronting their unique problems with courage and sagacity, though the size of their caseloads and the complexity of their problems appear to be increasing.

\section{Conclusion}

Many students of judicial administration have emphasized the difficulties experienced by metropolitan trial courts in seeing to it that the enormous caseloads are handled expeditiously, yet with something more than perfunctory routine. It is essential that they do see to it, for our legal system since Magna Charta has rested upon the guarantee that every man, regardless of his rank, wealth or station, shall have ready access to the judicial process, and to justice at its hands. "To no one will we sell, to no one will we refuse or delay, right or justice."

So says Magna Charta.

If metropolitan courts find this ideal difficult to achieve, they also know it to be worth the striving. 